\title{
Orchestra: Developing a Unified Open Architecture for Risk Management Applications
}

Alessandro Annoni ${ }^{1}$, Lars Bernard ${ }^{1}$, John Douglas ${ }^{2}$, Joseph Greenwood ${ }^{3}$, Irene Laiz ${ }^{4}$, Michael Lloyd ${ }^{5}$, Zoheir Sabeur ${ }^{4}$, Anne-Marie Sassen ${ }^{6}$, JeanJacques Serrano $^{2}$, Thomas Usländer ${ }^{7}$

${ }^{1}$ Joint Research Centre, European Commission, TP262, I-21020 Ispra

(VA), Italy \{lars.bernardlalessandro.annoni @jrc.it\}

${ }^{2}$ BRGM, 3, avenue Claude-Guillemin - BP 6009 - 45060 Orléans Cedex 2

-France, j.douglas@brgm.fr

${ }^{3}$ Research and Innovation, Ordnance Survey, Romsey Road, Southampton, SO16 4GU, UK, Joe.Greenwood@ ordnancesurvey.co.uk

${ }^{4}$ BMT Cordah Limited, 7 Ocean Way, Ocean village. Southampton SO14 3TJ, United Kingdom.

Zoheir.sabeur@bmtcordah.com

${ }^{5}$ AMRIE, 20-22 Rue Du Commerce, 1000, Belgium, amrie@info.org

${ }^{6}$ Atos Origin, sae. C/ Albarracin 25, 28037 Madrid, Spain, annemarie.sassen@atosorigin.com

${ }^{7}$ Fraunhofer IITB, Fraunhoferstr. 1, 76131 Karlsruhe, Germany

Thomas.Uslaender@iitb.fraunhofer.de 
2 Alessandro Annoni1, Lars Bernard1, John Douglas2, Joseph Greenwood3, Irene Laiz4, Michael Lloyd5, Zoheir Sabeur4, Anne-Marie Sassen6, Jean-Jacques Serrano2, Thomas Usländer7

\section{Abstract}

Due to organizational and technological barriers, actors involved in the management of natural or man-made risks cannot cooperate efficiently. In an attempt to solve some of these problems, the European Commission has made "Improving risk management" one of its strategic objectives of the IST programme. The integrated project Orchestra is one of the projects that recently started in this area. The main goal of Orchestra is to design and implement an open service oriented software architecture that will improve the interoperability among actors involved in multi-risk management. In this paper we will describe the goals of Orchestra and explain some of the key characteristics of the project. These are:

- The chosen design process of the Orchestra Architecture.

- How to further improve geospatial information and standards for dealing with risks

- How ontologies will be used to bring interoperability from a syntactical to a semantical level.

The paper ends with two examples demonstrating the benefits of the Orchestra Architecture. One is in the area of coastal zone management, and the other is related with managing earthquake risks.

\section{The current situation in risk management}

Increasing numbers of natural disasters have demonstrated to the European Commission and the Member States of the European Union the paramount importance of the natural hazards subject for the protection of the environment and the citizens. The flooding experienced throughout central Europe in August 2002 is the most recent example of the damage caused by unforeseen weather driven natural hazards. The summer of 2003 clearly showed the growing problem of droughts in Europe including the Forest Fires in Portugal with more than 90,000 ha of burnt areas. There is strong scientific evidence of an increase in mean precipitation and extreme precipitation events on the one hand and water shortages for certain regions on the other hand which implies that weather driven natural hazards may become more frequent. 
The European Spatial Development Perspective and new EC Regional Policy regulations emphasize the need of a better spatial planning and require new tools for the impact assessment of regional developments on natural and technological risks and vice versa. Now the new regulations for renewed Structural Funds and instruments for the period 2007-2013, adopted by the EC on 14 July 2004, foresee specific measures for "developing plans and measures to prevent and cope with natural risks".

The different types of risks (affecting the territory of the EU) need to be better addressed by an integrated approach to risk management. Prevention, preparedness and response, three major phases of risk management, usually involve a vast range of sectoral institutions and organisations at various administrative levels with different systems (monitoring, forecasting, warning, information, etc.) and services. Unfortunately, exchange of relevant information needed for dealing with risks is often limited to a raw data exchange level and true efficiency, in most cases, is hindered by administrative and legal boundaries as well as a lack of interoperability on the technical side.

Because natural and man-made disasters are not limited by administrative boundaries, cross-border aspects also need to be carefully considered and as a consequence major efforts are required to harmonise data and making services interoperable.

The application of different policies, procedures, standards and the lack of interoperability of systems, result in problems related to a efficient data management and information delivery, all critical elements of Risk Management. Interoperability based on standardisation will help close the gap between the different actors and is also expected to stimulate the development of an operational European service market supported by the sharing of procedures, interfaces and resources.

A substantial portion of IT expenditure in Europe supports the maintenance of thousands of legacy systems, the vast majority of which were not designed to work together. Recent events have underscored the need to be able to consolidate information from disparate systems to support citizen protection and security, disaster management, criminal justice, and other missions, crossing pan-European agency boundaries and extending into national, state and local government areas. One of the most urgent and important challenges currently facing governments is to get these systems to interoperate and share information. 
4 Alessandro Annoni1, Lars Bernard1, John Douglas2, Joseph Greenwood3, Irene Laiz4, Michael Lloyd5, Zoheir Sabeur4, Anne-Marie Sassen6, Jean-Jacques Serrano2, Thomas Usländer7

\section{The Orchestra project}

In an attempt to solve some of these problems, the European Commission has made "Improving risk management" one of its strategic objectives of the IST programme. The integrated project Orchestra is one of the projects that recently started in this area. The main goal of Orchestra is to design and implement an open service oriented software architecture that will improve the interoperability among actors involved in multi-risk management.

In order to realise this goal, the key objectives for the project are the following:

- To design an open service-oriented architecture for risk management that links spatial and non-spatial information services. In this context Orchestra will provide input to INSPIRE and GMES (see below).

- To develop the service infrastructure for deploying risk management services.

- To develop thematic services that are useful for various multi-risk management applications based on the architecture.

- To validate the Orchestra architecture and thematic services in a multirisk scenario.

- To provide software standards for risk management applications. In particular, the de facto standard of OGC and the de jure standards of ISO and CEN are envisaged to be influenced.

The Orchestra project started in September 2004. Currently the focus of the work is on understanding user needs, system requirements and an assessment of useful technologies. This is considered the necessary for input for design decisions for the Orchestra architecture. In the following we will first explain the process used to create the architecture, the so-called Orchestra Reference Model.

\section{The Orchestra Reference Model}

The architectural process of Orchestra is based on the principles of the following international standards:

- The Reference Model for Open Distributed Processing (ISO/IEC 10746 RM-ODP) is used for the structuring of ideas and documentation. 
- The OpenGIS Service Architecture (especially ISO/DIS 19119) is used for the taxonomy of the Orchestra services.

\section{Mapping of RM-ODP Viewpoints}

RM-ODP is an international standard for creating open, distributed processing systems. It provides an overall conceptual framework for building distributed systems in an incremental manner. The Orchestra architectural process uses the RM-ODP viewpoints for the structuring of ideas and their documentation. The mapping of the viewpoints to Orchestra is indicated in Table 1. As the Orchestra deployment will have the nature of a looselycoupled distributed system based on operational services rather than a distributed application based on computational objects, in Orchestra the "computational viewpoint" is referred to as the "service viewpoint".

\begin{tabular}{|c|c|c|}
\hline Viewpoints & Mapping to Orchestra & Usage example \\
\hline Enterprise & $\begin{array}{l}\text { Reflects the analysis phase in } \\
\text { terms of the system and the user } \\
\text { requirements as well as the } \\
\text { technology assessment }\end{array}$ & $\begin{array}{l}\text { Use case description } \\
\text { of a geoprocessing } \\
\text { service }\end{array}$ \\
\hline Information & $\begin{array}{l}\text { Covers the conceptual model of } \\
\text { all kinds of information with } \\
\text { their thematic, spatial, temporal } \\
\text { characteristics as well as their } \\
\text { meta-data. }\end{array}$ & $\begin{array}{l}\text { UML class diagram } \\
\text { defining the infor- } \\
\text { mation elements that } \\
\text { are used by the geo- } \\
\text { processing service }\end{array}$ \\
\hline $\begin{array}{l}\text { Computation- } \\
\text { al (referred to } \\
\text { as Service } \\
\text { Viewpoint) }\end{array}$ & $\begin{array}{l}\text { Covers the Orchestra services } \\
\text { that enable syntactical and se- } \\
\text { mantic interoperability and ad- } \\
\text { ministration across system } \\
\text { boundaries }\end{array}$ & $\begin{array}{l}\text { UML specification of } \\
\text { the geoprocessing } \\
\text { service }\end{array}$ \\
\hline Engineering & $\begin{array}{l}\text { Covers the mapping of the Or- } \\
\text { chestra service specifications to } \\
\text { the chosen service infrastruc- } \\
\text { ture }\end{array}$ & $\begin{array}{l}\text { Mapping of the UML } \\
\text { specification to } \\
\text { WSDL }\end{array}$ \\
\hline Technology & $\begin{array}{l}\text { Covers the technological choic- } \\
\text { es of the service infrastructure } \\
\text { and the operational issues of the } \\
\text { infrastructure. }\end{array}$ & $\begin{array}{l}\text { Usage of W3C Web } \\
\text { Services and UDDI }\end{array}$ \\
\hline
\end{tabular}

Table 1: Mapping of the RM-ODP Viewpoints to Orchestra

The Orchestra Reference Model covers all five viewpoints in the following manner: 
6 Alessandro Annoni1, Lars Bernard1, John Douglas2, Joseph Greenwood3, Irene Laiz4, Michael Lloyd5, Zoheir Sabeur4, Anne-Marie Sassen6, Jean-Jacques Serrano2, Thomas Usländer7

- The analysis phase is described as part of the Enterprise Viewpoint.

- The design phase encompasses the harmonised specification of the Information and Service viewpoint resulting from requirements of the Enterprise viewpoint. The result is the Orchestra architecture that is, by definition, a platform-neutral specification according to the requirements of ISO/DIS 19119 (i.e. specification in UML).

- The Orchestra architecture does not cover the Engineering and Technology viewpoints.

- The aspects of the Engineering and Technology viewpoints are combined in one or more process steps. Each step represents one mapping to a specific service infrastructure (e.g. W3C Web Services) and leads to a platform-specific Orchestra Implementation Specification.

\section{Compliance with the OpenGIS Service Architecture}

The Orchestra architecture is a "simple service architecture" and shall use the service taxonomy of the Open GIS Architecture (ISO/DIS 19119). Thus, Orchestra will provide human interaction services (e.g. catalogue or map viewers), model/information management services (e.g. feature and map access services, query support services), workflow/task services (e.g. service chaining support), processing services (e.g. statistical calculation), communication services (e.g. web services) and system management services (e.g. authorisation support).

\section{Analysis and Design Process}

The Orchestra architecture is being designed in an iterative way recognising the fact that both the requirements of the system and end users and the technological progress in the IT market and in IT standardisation have a dynamic nature and cannot be completely caught in a one-shot design. Thus, a global iteration cycle between the analysis and the design phase of the architecture is foreseen (see Figure 1).

A consolidation process in-between ensures that, at a defined point in time, there is a common understanding of the system requirements, the user requirements and an assessment of the current technology as a foundation to design the Orchestra architecture.

System requirements encompass all aspects that today prevent interoperability between systems. They are expressed in terms of architectural 
properties that a system should follow in order to improve the exchange, sharing and using of information across system boundaries.

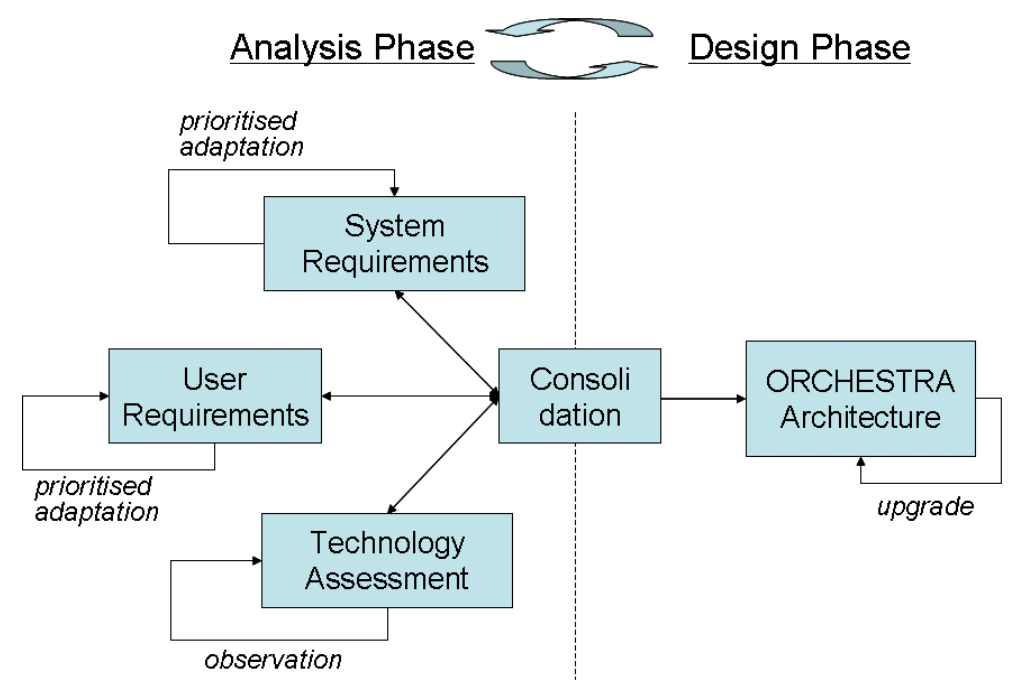

Figure 1: Dynamic Orchestra Architectural Process

User requirements, on the one hand, represent the view of the end user of the Orchestra system that is being specified independent of the technological foundation of the system. It is expressed in terms of end-user services, information presentation and availability requirements and nonfunctional aspects such as trustworthiness of information, response time or quality of service. On the other hand, they comprise the view of the system engineer that will build thematic services (e.g. for flood or fire forecast). Here, user requirements are expressed in terms of the domain-specific information model (ontology) that has to be supported by the principal information management capabilities of the Orchestra platform.

Both the system and the user requirements are dynamic in the sense that they will be prioritised and adapted in local iteration cycles due to the result of the consolidation process.

Technology assessment is also a continuous process. Orchestra aims at building the architecture on top of technologies, tools and products that are either standard approaches or have proven to be successful in solving interoperability problems in deployed use-cases.

The dynamic nature of the input factors of the Orchestra architecture naturally leads to an iterative architectural design process. Various but 
8 Alessandro Annoni1, Lars Bernard1, John Douglas2, Joseph Greenwood3, Irene Laiz4, Michael Lloyd5, Zoheir Sabeur4, Anne-Marie Sassen6, Jean-Jacques Serrano2, Thomas Usländer7

controlled upgrades of the Orchestra architecture will be required to adapt the architecture to the changing needs.

In the following two sections of this paper we will highlight two important technologies for Orchestra: geographic information and ontologies for improvement of semantic interoperability. We will explain what Orchestra will contribute to the state of the art in these fields.

\section{Geographic information services for risk management}

Geographic information is involved in all phases of risk management processes - from prevention to immediate reaction. The geospatial aspects may be explicit (e.g. topographic maps providing background information) or hidden (tables about population distribution in an affected area). In the same way either dedicated tools are used to analyse or incorporate geospatial aspects (e.g. the usage of a GIS by a GI expert) or the information is integrated via interoperable GI components or GI services in a specific risk management application. Orchestra focuses on the latter case.

The transition from closed and monolithic GIS to open and interoperable GIS introduces a paradigm shift in the development of GIS-standards. Standards do not any more focus on formats for the file exchange of geodata but are directed to the specification of service interfaces. These services provide geoinformation that are processed according the user's query and their specific needs, e.g. a specific part of the cadastre, a fastest route from $A$ to $B$, a thematic map on the current ozone pollution etc.

\section{Interoperable GI Services}

On-going activities to realise interoperable GI services currently mainly focus on encoding and accessing geographic information in an interoperable manner. The existing (partly draft) ISO standards and OGC specifications cover encoding and accessing geographic information to achieve interoperable GI services. Thus following the OGC service taxonomy this work falls mainly into the category model/information management services. However, specifications to define interoperable GI services to process spatio-temporal information (processing services) need still to be researched and there is an urgent need to define the respective specifications to support risk management applications as intended by Orchestra. Exam- 
ples of functionalities that need to be covered by these geoprocessing services are:

- Weighted combination of different geoinformation layers to support assessment and spatial decisions

- Spatial and topological operators (buffer, generalisation, etc.)

- Feature extraction services, e.g. to operate on remote sensing data

- Geostatistical operators to extract key values or aggregate spatial information.

Moreover Orchestra will investigate on interoperability of GI services with spatio-temporal simulation models to ease the incorporation of e.g. flooding or weather forecast simulations in risk management applications.

Interoperable GI services are one cornerstone for the successful implementation of Spatial Data Infrastructures (SDI). SDI evolve all over Europe on institutional, regional and national levels. In 2001 the European Commission started the INSPIRE initiative (INfrastructure for SPatial InfoRmation in Europe; http://inspire.jrc.it/home.html) to streamline national SDI developments with respect on supporting European environmental policies. The initiative intends to trigger the creation of a European Spatial Data Infrastructure (ESDI) that delivers to the users integrated geospatial information services from various distributed sources, crossing institutional and political boundaries. The target users of INSPIRE include policymakers, planners and managers at European, national and local level and the citizens and their organisations.

\section{European Directive on Infrastructure for Spatial Information in Europe (INSPIRE)}

Following 3 years of intensive collaboration with Member States experts and stakeholder consultation, the European Commission has adopted on the July 2004 a proposal for a Directive establishing an infrastructure for spatial information in the Community (INSPIRE) (COM(2004) 516 final).

The adoption of the proposal marks an important step on the way forward to a European-wide legislative framework that helps in achieving an ESDI. This proposal does not only address policy related issues concerning the development of an ESDI but also dedicates three chapters to the technical requirements that have to be fulfilled by the member states to establish the ESDI. These three chapters are on Metadata, Interoperability of spatial data sets and services, and Network services. Under these chapters 
10 Alessandro Annoni1, Lars Bernard1, John Douglas2, Joseph Greenwood3, Irene Laiz4, Michael Lloyd5, Zoheir Sabeur4, Anne-Marie Sassen6, Jean-Jacques Serrano2, Thomas Usländer7

the proposal list general requirements on these issues as well as it formulates the requirement to adopt appropriate implementing rules.

During the INSPIRE preparatory phase (2005-2006) the ORCHESTRA project will provide input towards the drafting as well as the piloting of the INSPIRE implementing rules in the risk management domain. The first input can be expected on the topic of the INSPIRE network services.

The establishment of an ESDI will represent significant added value for - and will also benefit from - other Community initiatives such as Council Regulation (EC) No 876/2002 of 21 May 2002 setting up the Galileo Joint Undertaking (OJ L 138, 28.5.2002) and Global Monitoring for Environment and Security (GMES): Establishing a GMES capacity by 2008 $(\mathrm{COM}(2004) 65$ final). In order to exploit the synergies between these initiatives, Member States should consider using the data and services resulting from Galileo and GMES as they become available, in particular those related to the time and space references from Galileo.

\section{The use of ontologies for improved semantic interoperability}

Where there are many distributed and heterogeneous sources of information and application services to be used then the key is interoperability between them. This needs to work on at least three levels; the syntax level, the structural level and the semantic level. To date most standard work has focused on the syntax of communicating between disparate software services, for example the Web Map Service standard of the OGC, which specifies the syntax for communicating between the mapping client and the service. Work has also concentrated on the structure of the data used in those interactions such as Simple Feature Specification of the OGC which allows structured data to be shared between systems. These two aspects make the physical connectivity and exchange of data possible and enable a distributed architecture to be realized.

However the content of the information in the distributed systems being connected may be referring to substantially different things and consequently not interoperate at the level of its semantics. For example in the risk management domain the term 'bank' in different data sources could mean 'a steep natural incline' or 'a business establishment in which money is kept'. One set of data is clearly suitable for use in a flood modeling application and the other is not! This is further complicated in multiple risk 
management scenarios where the information with different terminology from multiple information communities must be interpreted together.

In order to resolve this semantic interoperability when sharing data between systems the meaning of the terms must be stated so that the differences can be resolved by the computer. This can be done in an ontology which in a computer science setting is a 'specification of a conceptualization'. It formally describes a set of concepts and the relationships that hold between them in a given context in a logical manner so the semantics can be interpreted by machines. The W3C have defined the OWL (Web Ontology Language) standard for the representation of ontologies to describe the semantics of disparate resources on the network.

The approach in Orchestra will be to define ontologies for common domains of risk management such as flooding or forest fire and the common concepts of risk management that bind these domains. The rich high level formal semantics within these ontologies should be capable of representing the abstract concepts and relations such as the causes, propagators and effects of risks. The simpler semantics of individual data sources and applications are represented in their own ontologies and are then mapped to the rich high level semantics of these ontologies This allows heterogeneous and abstract semantics of different data sources and applications to be interpreted through the richer semantics of the domain. By having a common semantics to which data and services are ultimately mapped it improves the selection and comparison of data sources based on their content and it becomes possible for the machine to infer whether two data sources are comparable or suitable for use in an application service. The formal representation of the common concepts of risk management also provide a common semantics to support cross domain query in multi risk management. For example the data about the results of forest fire can act as an input to understanding the increased risk to flooding due to mass vegetation changes.

To allow the ontologies to be used to bind together the different data sources and services of the Orchestra architecture they need to be mapped to the common meta information model and be processed by the core services. The project will define the mapping of the ontologies to the meta information model of the Orchestra architecture to which the different services and data sources will also be referenced. This common structure for using meta information will be used to combine the different services by providing the relationship to the syntax and structural description of in- 
12 Alessandro Annoni1, Lars Bernard1, John Douglas2, Joseph Greenwood3, Irene Laiz4, Michael Lloyd5, Zoheir Sabeur4, Anne-Marie Sassen6, Jean-Jacques Serrano2, Thomas Usländer7

formation. Semantic web-services will need to be incorporated into the architecture as part of the core services to expose and manipulate the ontologies. These at a minimum include ontology management and storage services, inference services to infer the semantic equivalence between different data sources and services and query brokering services. These are required to transform the semantics into syntax and structural connectivity to enable access to the different data sources.

Through the meta information model and the services of the Orchestra architecture Orchestra will seek to provide a framework in which semantic interoperability can start to be achieved in addition to and integrated with the syntactical and structural interoperability. The key benefits to using formal and explicit semantics lie in the area of selecting and combining disparate information from a variety of sources to be used for a particular risk management task. With a functional semantic layer the differing uses of terminology across different risk management systems is no longer a barrier to the productive sharing of information and approaches. The appropriate use of data for a given application service or function can also be matched to ensure the end results are consistent. In an open architecture this allows multiple organization to share information and collaborate as the formal semantic enables plurality of views particularly in multi-risk scenarios where different information communities must work together.

\section{Examples of the use of Orchestra}

The Orchestra architecture will not take the form of a ready to use application for risk management. To the contrary, it should be considered as a collection of services, tools and methodologies that so-called system users can use to develop risk management applications for end users. It is our vision that chains of cooperating services will become reality and that system users can add value to already existing services. They can for instance combine services for one risk with services for another risk, and that way develop a multi-risk management application. There will be less need for reinvention of the wheel, and more effort can be spend on creative solutions for specific problems.

The Orchestra architecture will be generic in the sense that it should provide basic functionality that is useful in applications for any kind of risk (natural or technological), also in cross border situations. Based on this architecture, the project will develop a few thematic services that are 
useful in various risk management applications, such as a cadastre service, a weather service, etc.

A large part of the project will be dedicated to the validation of the Orchestra architecture and thematic services. We will now describe two possible scenarios for the use of Orchestra. The first one is related to coastal zone management, and the second one to earth quake risk management.

\section{An example of the use of Orchestra for risk management at coastal zone}

The study of the environmental risks which may be generated from maritime transport activity in coastal European waters requires the establishment of advanced modelling techniques and evaluation benchmarks. The support of a generic evaluation of the environmental risks within an open information system infrastructure is key for improving the risk management methodology.

In Orchestra, various numerical modelling applications could be deployed to assess the environmental risks induced by ship traffic activity at coastal zones. This can be efficiently achieved through a generic sharing of common toxicity, traffic networks, coastal zone environmental databases and numerical modelling kernels. The generic sharing of data information is formalised through advanced knowledge modelling at coastal zone, including standard data and meta-data access methods. Maritime transport activity could induce the multiple risk of introducing anti-foulants, ballast waters, oil and chemical spills, and atmospheric emissions into coastal waters and coastal zones. Ship traffic spatial networks in European coastal waters can be geographically identified, updated in time and shared within common databases (Figure 2). The generic access to such geospatial information within Orchestra will lead to rapid risk management of ship traffic in European coastal waters.

The engendered multiple risks can be predicted through multi-modelling the fate of anti-foultants such as TBT, alien organisms in ballast waters and $\mathrm{SO}_{\mathrm{x}} / \mathrm{NO}_{\mathrm{x}}$ gases in the atmosphere following on ship traffic network within a region ship traffic network of interest. The various discharges of ballast waters, anti-foulants and gas emmissions could lead to quantifiable risks of multiple orders around coastal zone environments, including health risks. For instance, TBT anti-foulants exposure may lead to marine species genetic disorders; ballast waters could introduce alien marine organisms and diseases and; gas emissions cause poor air quality and respiratory problems around the same zone of interest. Oil spills could not only 
14 Alessandro Annoni1, Lars Bernard1, John Douglas2, Joseph Greenwood3, Irene Laiz4, Michael Lloyd5, Zoheir Sabeur4, Anne-Marie Sassen6, Jean-Jacques Serrano2, Thomas Usländer7

damage marine organisms, but also damage commercial activities such as fishing and tourism, and hence contribute to raising unemployment levels in coastal working communities.

The above mentioned risks could themselves induce secondary risks on local economies at coastal zone, i.e. fishing and leisure industries, and may contribute to unemployment levels within coastal working communities.

The various types of risks are established as probability of occurrences of the so-called Predicted Environmental Concentration (PEC) and compared to critical exposures; the so-called No Effect Concentration (NEC) value. Spatial hazard maps can therefore be predicted within coastal zone and updated according to changes in environmental conditions and ship traffic activity with time (Figure 3). Hazards maps will lead to the dynamic evaluation of multi-risks and their probability of exceedence with respect to EU and international statutory criteria. These are with respect to air and water quality standards but also ecosystem toxicity thresholds. The economic indicator thresholds are much more challenging during the evaluation exercise but can still be implemented as additional information layers within the Orchestra model applications if historical economic indicators are available for the regions of study.

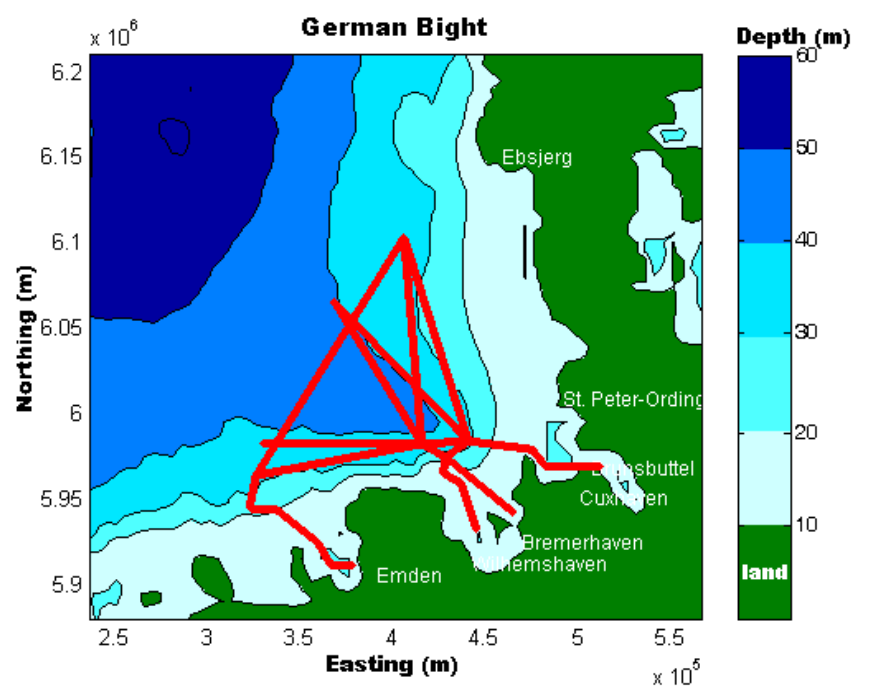

Figure 2 Illustrative ship traffic network in the German Bight 

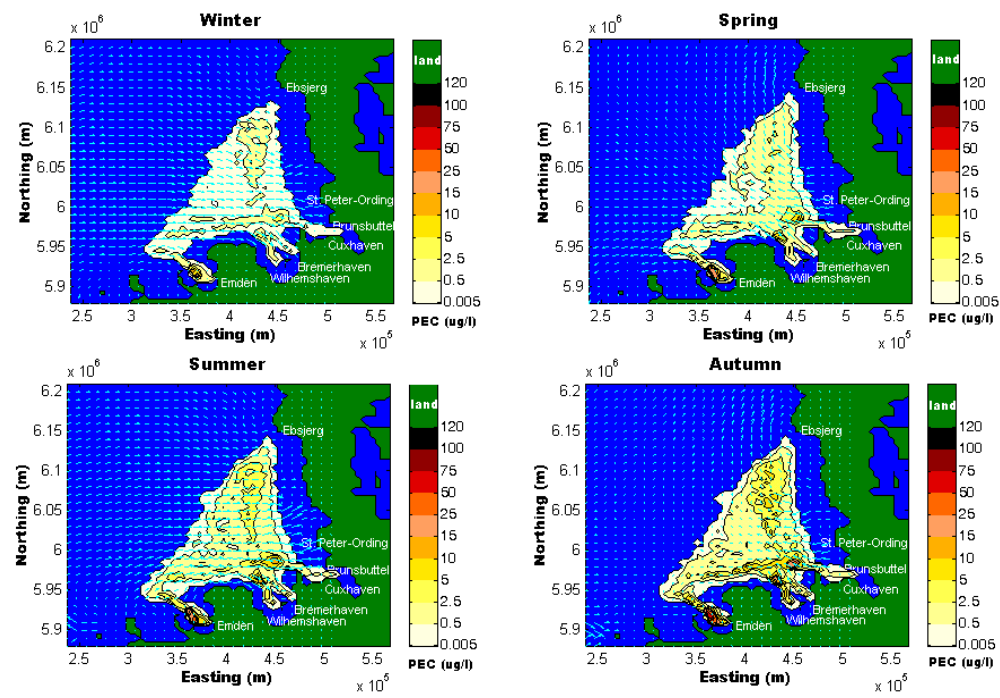

Figure 3 Illustrative TBT Exposures in the German Bight

\section{An example of the use of Orchestra for earthquake risk management}

Earthquakes can occur in border regions (both national and international), e.g. the 1976 Friuli earthquake sequence that caused damage in Italy and in Slovenia. They can induce other potentially damaging events, such as landslides (e.g. the $2001 \mathrm{El}$ Salvador earthquake where the biggest single lost of life was caused by a landslide triggered by the earthquake) or fires (e.g. the 1923 Kanto Plain earthquake where the fires following the earthquake caused many more causalities than the actual earthquake shaking). Because of the potentially catastrophic nature of large earthquakes, which can affect all aspects of society, their correct management relies on close cooperation between different organisations at different levels. For these reasons earthquake risk management is a good example of the type of risk that is of particular interest to Orchestra. Earthquake risk management is an interesting contrast to coastal zone management because earthquakes are a rapid-onset hazard (the strong shaking that causes damage during an 
16 Alessandro Annoni1, Lars Bernard1, John Douglas2, Joseph Greenwood3, Irene Laiz4, Michael Lloyd5, Zoheir Sabeur4, Anne-Marie Sassen6, Jean-Jacques Serrano2, Thomas Usländer7

earthquake usually lasts for less than one minute), although the effects can last for decades, whereas coastal zone hazards are usually slow-onset hazards. In addition, the main technique for managing earthquake risk is to reduce the vulnerability of the elements at risk by using better construction techniques whereas coastal zone risk management also includes efforts to reduce the actual hazard (a step that is impossible for earthquakes). For these and other reasons it is a big challenge to develop an architecture that is appropriate for both these risks (and others).

Orchestra will help to improve the management of earthquake risk in Europe by facilitating easier data exchange between involved parties. For example, the estimated level of seismic hazard often does not exactly match at national and international borders due to differences in input data and methodology, whereas in reality earthquakes do not respect human borders. Similar problems can occur for building vulnerability assessments in different countries due to differences in the way this is performed and because of the difficulty in accessing vital information. Therefore the assessed earthquake risk across borders is difficult to compare and consequently it is difficult assign priorities to its management. This leads to a non-optimal allocation of resources and therefore waste and higher real risks in some regions than expected.

\section{Concluding remarks}

The Orchestra project (www.eu-orchestra.org) started in September 2004 and will run until August 2007. The following organisations are involved in the project:

- Atos Origin, Spain

- European Commission - DG Joint Research Centre, Italy

- Hochschule fuer Technik und Wirtschaft des Saarlandes, Germany

- Open Geospatial Consortium (Europe) Limited, United Kingdom

- BRGM, France

- Ordnance Survey, United Kingdom

- Fraunhofer IITB, Germany

- ARC Seibersdorf research GmbH, Austria

- Eidgenoessische Technische Hochschule Zuerich, Switzerland

- Intecs, Italy

- DATAMAT S.p.A., Italy

- TYPSA, Spain 
- BMT Cordah Limited, United Kingdom

- The Alliance of Maritime Regional Interests in Europe, Belgium

The project will work together closely with two other Integrated Projects in the field called WIN (http://www.win-eu.org) and OASIS (www.oasis-fp6.org). WIN will concentrate more on organisational issues relevant for improved interoperability in risk management and OASIS focuses on crisis management. The three projects will use the same architectural principles and make their results interoperable. These results will be provided as input to INSPIRE and to GMES (Global Monitoring for Environment and Security, www.gmes.info).

\section{References}

- Craglia, M., A.Annoni, R.S. Smith and P. Smits - 2002 -Spatial Data Infrastructures: Country Reports- GINIE - EUR 20428 EN (2002) http://wwwlmu.jrc.it/ginie/doc/SDI_final_en.pdf

- Craglia, M. , A. Annoni, M. Klopfer, C. Corbin, G Pichler \& P. Smits, 2003. GINIE Book: Geographic Information in the Wider Europe. GINIE, 2003, http://wwwlmu.jrc.it/ginie/doc/ginie_book.pdf

- European Commission, 2003 - "INSPIRE State of Play Reports- Spatial Data Infrastructures in Europe : State of play 2002", http://inspire.jrc.it/state_of_play.cfm

- European Commission, 2003 - "INSPIRE State of Play Reports- Spatial Data Infrastructures in Europe : State of play 2002", http://inspire.jrc.it/state_of_play.cfm

- European Commission, 2004. Proposal for a Directive "establishing an infrastructure for spatial information in the Community (INSPIRE)" $\operatorname{COM}(2004) 516$ final. (http://inspire.jrc.it)

- Nebert, D, Ed. 2001 - "Developing Spatial Data Infrastructures: The SDI Cookbook, Version 1.1", Global Spatial Data Infrastructure, Technical Committee

- Smits, P., Ed. 2002. INSPIRE Architecture and Standards Position Paper. (http://inspire.jrc.it) 